\title{
Review of Research in Japan on Electromagnetic Force Induced Vibration and Noise from an Electrical Motor*
}

\author{
Koki SHIOHATA** \\ **Department of Mechanical Engineering, Ibaraki University \\ 4-12-1 Nakanarusawa, Hitachi, Ibaraki, Japan \\ E-mail: shiohata@mx.ibaraki.ac.jp
}

\begin{abstract}
An induction motor and synchronous motor are applied as a source of drive for machines such as power plants, home appliances and cars. Recently, electrical efficiency have been improved and mechanical structures have become lighter and smaller. As a result of these trends, mechanical vibration and noise are increasing. Vibration and noise caused by electromagnetic force must be reduced to provide a comfortable environment. To satisfy these needs, a system to simulate vibration and noise precisely and effectively at the mechanical design stage is needed. Such a simulation system would reduce the time needed for experimentation and reduce the length of development periods and costs of production.
\end{abstract}

Key words: Vibration of Rotating Body, Forced Vibration, Self-Excited Vibration, Electromagnetic Induced Vibration, Torsional Vibration

\section{Introduction}

An electric motor is applied as actuators for kinds of machines. In particular, they are used in the field of home electric machines, automobile cars, mechatronics and information devices and are requested to be small size and high power. In order to satisfy the requests, the electromagnetic force induced vibration and noise have been increasing. Conventionally, the developments of an electric motor have been served for electrical researcher. However, low vibration and noise are requested for amenity life space. In the work, research on vibration and/or noise from an electric motor is reviewed. The papers to be reviewed are mainly restricted to be published in Japan. Almost papers are published to major two Japanese Journals such as Japan Society of mechanical Engineers and IEEJ, and one paper is published to IEEE in the past 25 years. All papers are selected from the region of vibration and noise in electric motors. These selected papers are listed in the reference sections. The contents of the papers of electromagnetic force induced vibration and noise, natural frequency, rotor and structural vibration, case study are introduced with brief comments to trace the development of research in Japan.

\section{General Description}

For small size and high power electric motors, low vibration and noise are very important problems to be solved. Main phenomena are caused by electromagnetic force. In order to solve the problems, modeling and analysis method of natural frequency analysis and vibration response, simulation method and reduction method are researched and listed. Electromagnetic force is caused by electric flux between rotor core and stator core and calculated by Maxwell's equation. In the electromagnetic force, harmonic components are included and the frequency of them determined by the power source, slot combination and 
the number of poles.

\section{Electromagnetic force}

Electromagnetic force is generated in the gap between rotor core and stator core and calculated by Maxwell's Equation using electrical flux. The electric force is generated in the radial direction, axial direction and circumferential direction. The harmonics components are exciting force for structural vibration and radiated noise. In this work, papers on an electric motor excitation force are reviewed.

In Ref.(1), Ota, et al introduce the direct measurement method of motor excitation force transmitted to mechanical structures using a test system with a capacitor motor and a load cell. In the paper, motor is supported by rigid support. In Ref.(2), Ota, et al introduce the estimation of motor excitation force by indirect method, in which hybrid method and elastic support method are introduced. The former is concerned with an identification of a motor excitation using a measurement value of acceleration in the circumferential direction and FEM simulation. The later is concerned with improved the Ref.(1) by elastic support. Ref.(3) is concerned with the estimation method of the excitation force of an electric motor by inverse system. In Ref.(4), Ota et al. investigate the calculation method of motor excitation forces caused by torque pulsation. In the paper, force of twice the power supply frequency such as $2 f$ component is noticed. From the research, it is experimentally obvious that the torque pulsation works as motor excitation force which vibrates the motor structure.

\section{Simulation for electromagnetic force induced vibration and noise}

Vibration and noise caused by electromagnetic force must be reduced to provide a comfortable environment. To satisfy these needs, a system to simulate vibration and noise precisely and effectively at the mechanical design stage is needed. Such a simulation system would reduce the time needed for experimentation and reduce the length of development periods and costs of production. The analysis flow of electromagnetic force induced vibration and noise is as follows. (1) calculation of electromagnetic force, (2) transformation from electromagnetic force to structure exciting force, (3) calculation of structural vibration and (4) calculation of acoustic analysis. In Ref.(5), Noda et al analyze the relationship of exciting force such as electromagnetic radial force and vibration mode of the stator. As an electromagnetic radial force in analysis, the continuous distributed force and discrete multipoint exciting force are applied. In the paper, vibration behavior of the stator core is discussed analyzed theoretically, numerically and experimentally with respect to modes, frequency and phase of exciting force. In Ref.(6), Shiohata, et al discuss on accurate modeling and calculation of electromagnetic force induced vibration and noise for prototype induction motor. For the system of an induction motor, Shiohata and others have reported the technique of being consistent and analyzing electromagnetism vibration and noise by two-dimensional electromagnetic-force analysis, three-dimensional structure vibration analysis, and three-dimensional acoustic field analysis. In the paper, SMORC(Space Modal Resonance Criteria)is also proposed to determine the quantitative extent of the resonance numerically between vibration of the stator and higher-order harmonic components of electromagnetic force. Furthermore, comparing with the results of experiment and simulation, high precision of vibration model and noise analysis are verified.

\section{Natural frequency}

A large vibration is occurred when natural frequency of motor structure equals to that of electromagnetic force. That is resonant phenomena. And large noise is also occurred. That is why natural frequency of motor structure must be accurately predicted to reduce the 
large vibration and noise. In Refs.(7)-(9), Shiga discusses natural frequency of the radial direction of stator core consisting from teeth, cylindrical part and laminate of stator core. In Ref.(10), in order that Iwata et al improve the computational accuracy of natural frequency, he evaluates the flexural rigidity of the laminated stator core experimentally, and is modeling with equivalent flexural rigidity. Noda, et $\mathrm{al}^{(11,(12),(14))}$ and Itomi et $\mathrm{al}^{(13),(15)}$ investigate the natural frequency of the stator core in an induction motor. In Ref.(11), the simplified calculation method of natural frequency is proposed. In the method, the authors provide a coupling vibration model with two degrees of freedom which consists of double ring(stator core and coil end) connected by spring. In Ref.(12), the press fit as contact problem by finite element method is considered and modeled by spring elements with radial and circumferential spring constant at contact points to calculate accurately natural frequency of stator core pressed in frame. In Ref.(13), t he natural frequencies of a totally enclosed motor are studied by FEM analysis. In FEM analysis, the stator core without coil, coil and frame are considered and Young's modulus of coil and the spring constants at contact points between stator core and frame are used. In Ref.(14), the stator core and frame are modeled with dual ring, and the effects of the tight fit between stator core and frame to the natural frequencies are investigated. In Refs.(15), the Young's moduli of windings which are composed by the enameled wires, insulation films and varnish are investigated experimentally.

\section{Vibration Analysis Method}

\subsection{Structural Dynamics}

In Ref.(16) and (17), Hino et al propose the analysis method of a whole motor. In Ref.(16) , a compact motor used as a part of vacuum cleaner is divided into substructures as a rotor, a stator and two frames and the modal characteristic of each structure excluding rotor is measured by impact testing experimentally. And the modal parameter of rotor is obtained by FEM analysis. Modal characteristic obtained from the four substructures is synthesized by using mode synthesis method, and the dynamic characteristic of the whole structure is analyzed. In Ref.(17), analysis method in Ref.(16) is extended to the complex mode synthetic method using complex natural mode and is able to apply to a general viscous damping system.

\subsection{Rotor Dynamics}

In this work, a vibration of rotating shaft of an electric motor caused by a rotor manufacture error and caused by the electromagnetic pull force is reviewed. In Ref.(18) by Nagaya and Ikeda, vibration and vibration isolation method of a motor due to a whirling of rotating shaft is described in consideration of the magnetic pull force which occurs in the gap of a rotor and a stator. In Ref.(19), for a two poles induction motor, Iwata et al is discussing experimentally and analytically the bending vibration characteristics of the rotating shaft caused by structural factors of the rotor, such as eccentricity of a rotor. In the paper, the dominant vibration phenomena for the structural factor are described. In Ref.(20), Kanzaki, et al studied the electromagnetic exciting force of two times the power source frequency caused by unbalance of the magnetomotive force on the stator core. The unstable oscillation denoted by the Matthew equation by electromagnetic excitation force for a three-phase induction motor is clarified by a numerical simulation, and it is verified in an experiment. In Ref.(21) by Iwatsubo et al, the multi-degree-of-freedom system vibration model by the finite element method was built for the two and four poles induction motor, and relation between an electrical parameter and an unstable region was clarified by the numerical simulation. 


\section{Reduction of Vibration and Noise from Motor}

In an electrical motor, structural factors affect the electromagnetic force induced vibration and noise. By clarifying these factors, vibration and noise are reduced or trouble of vibration and noise is resolved. In Ref.(22), Adachi and Taninaga clarify experimentally the factors which effect the noise caused from automotive direct-current motor. From the result, a countermeasure which reduces the noise is presented for an automotive direct-current motor and the noise reduction is achieved. In Ref.(23), Matsubara et al describe the finite element model for rotor-bearing systems, which has been used to estimate the natural frequency of the rigid-body-vibration mode largely affecting electromagnetic force induced vibration and noise in a small induction motor. By the finite element model, rotor structure which avoids a resonance is proposed and its effect is verified experimentally. In Ref.(24) by Yoshikuwa, et al, effect of manufacturing error on the electromagnetic force induced vibration of brushless DC motors is discussed. In the paper, manufacturing error means eccentricity and roundness. In Ref.(25) by Shiohata, et al, the electromagnetic force induced vibration and noise from universal motor with eccentricity are discussed experimentally. In Ref.(26), Noda, et al discuss in the induction motor the relation between variation of the natural frequency and temperature in electromagnetic force induced noise is analyzed and the cause of noise variation with temperature is clarified. In Ref.(27) by Kobayashi, et al, electromagnetic-force analysis of induction motors with three types of slot combinations of a rotor and a stator, and harmonics analysis are conducted, and the validity was clarified experimentally. Moreover, current frequency and the relation of noise are experimentally clarified about these three types. In Ref.(28), Itagaki, et al clarify experimentally in a small induction motor that the abnormal vibration is a forced self-excited vibration of the vibratory system with an axial nonlinear spring due to ball bearing. In Ref.(29) by Nakamura, the generation mechanism of the unusual noise generated from axial flow fans is investigated, and it has been clarified that the harmonic torque of the induction motor which drives the fan is resonant with the torsional vibration of the rotary systems. In the paper, in order to prevent the generation of this unusual noise, a method of mechanically avoiding resonance by setting of torsional rigidity in the rotation axis and a method of reducing generation of harmonic torque of the induction motor are proposed and experimentally confirmed.

\section{Conclusion}

In this work, it reviewed from the domestic typical paper magazine in the past 25 years at a mechanical standing about the research on vibration and noise which occur with electromagnetic force during the rotation of a motor. There are not so many papers in the mechanical field. Subsequently, many researches on countermeasure method of electromagnetic induced vibration and noise have been reported. This tendency is considered to be natural as a mechanical researcher. For this reason, there are few papers currently systematically studied even in from electromagnetic force to structural vibration and noise analysis.

It is expected that needs of an electric motor, especially the small size and high power electric motor increase as a source of a drive of the machines including a car in future. Therefore, the research of electromagnetic induced vibration and noise will have influence important for development of an electric motor more and more.

The reviewer hopes that Japanese mechanical researchers understand electromagnetism vibration of a motor and noise as a composite phenomenon of electricity and machine, and expects they develop this field as multi-physics type research. 


\section{References}

1. Ota, H., Sato, T., Okamoto, J., Nagai, M., Nagahashi, K., Direct Measurement of Motor Excitation Force, Trans Jpn. Soc. Mech. Eng., (in Japanese), Vol. 70, No. 700, C(2004), p. 3360

2. Ota, H., Sato, T., Estimation of Motor Excitation Force by Indirect Method, Trans Jpn. Soc. Mech. Eng., (in Japanese), Vol. 71, No. 706, C(2005), p. 1813

3. Ota, H., Sato, T., Estimation of Motor Excitation Force by Inverse System, Trans Jpn. Soc. Mech. Eng., (in Japanese), Vol. 72, No. 714, C(2006), p. 355

4. Ota, H., Sato, T., Okamoto, J., Nagai, M., Nagahashi, K., Calculation of Motir Excitation Force Caused by Torque Pulsation, Trans Jpn. Soc. Mech. Eng., (in Japanese), Vol. 70, No. 700, C(2004), p. 3363

5. Noda, S., Ishibashi, F., Ide, K., Vibration Response Analysis of Induction Motor Stator Core(Vibration Response of Distributed Excitation and Multipoint Excitation), Trans Jpn. Soc. Mech. Eng., (in Japanese), Vol. 59, No. 562, C(1993), p. 1650

6. Shiohata, K., Nemoto, K., Nagawa, Y., Sakamoto, S., Kobayashi, K., Itou, M., Koharagi, H., A Method for Analyzing Electromagnetic-Force-Induced Vibration and Noise Analysis.

7. Shiga, M., Natural Frequencies of Stator Core in Induction Motor ( $1^{\text {st }}$, Vibration Characteristics in the Radial Direction), Trans Jpn. Soc. Mech. Eng., (in Japanese), Vol. 50, No. 451, C(1984), p. 464

8. Shiga, M., Natural Frequencies of Stator Core in Induction Motor (2nd, Analysis of Natural Frequencies in the Radial Direction), Trans Jpn. Soc. Mech. Eng., (in Japanese), Vol. 51, No. 461, C(1985), p. 26

9. Shiga, M., Natural Frequencies of Stator Core in Induction Motor, Trans Jpn. Soc. Mech. Eng., (in Japanese), Vol. 51, No. 471, C(1985), p. 2760

10. Iwata, Y., Sato, H., Morioka, Y., Natural Frequency of Rotor Core, Trans Jpn. Soc. Mech. Eng., (in Japanese), Vol. 57, No. 544, C(1991), p. 3748

11. Noda, S., Suzuki I., Itomi, K., Ishibashi, F., Mori, S., Simple Calculation Method for Natural Frequencies of Stator Core in Induction Motor, Trans Jpn. Soc. Mech. Eng., (in Japanese), Vol. 60, No. 578, C(1994), p. 3245

12. Noda, S., Suzuki I., Itomi, K., Ishibashi, F., Mori, S., Ikeda, Y., Natural Frequencies of Stator Core with Frame in Induction Motor, Trans Jpn. Soc. Mech. Eng., (in Japanese), Vol. 61, No. 591, C(1995), p. 4195

13. Itomi, K., Noda, S., Suzuki I., F., Ishibashi, F., Analysis for Natural Frequencies of Stator Core in Induction Motor, Trans Jpn. Soc. Mech. Eng., (in Japanese), Vol. 64, No. 624, C(1998), p. 2833

14. Noda, S., Itomi, K., Ishibashi, F., Ide, K., Contact Pressure and Natural Frequencies in Dual ring (Experimental Study for Natural Frequencies of Stator Core in Induction Motor), Trans Jpn. Soc. Mech. Eng., (in Japanese), Vol. 65, No. 629, C(1999), p. 23

15. Itomi, K., Noda, S., Ishibashi, F., Yanawaki, H., Young's Modulus of Windings on Finite Element Method for Natural Frequency Analysis of Stator Core in Induction Motor, Trans Jpn. Soc. Mech. Eng., (in Japanese), Vol. 68, No. 669, C(2002), p. 23

16. Hino J., Tanizumi, K., Yoshimura, T., Nagamatsu, A., The Vibration Analysis of a Compact Motor by the Substructure Synthesis Method(1st Report, The Mode Synthesis Method for a Compact Motor Used as a Part of Vacuum Cleaner), Trans Jpn. Soc. Mech. Eng., (in Japanese), Vol. 53, No. 491, C(1987), p. 1384

17. Hino J., Tanizumi, K., Yoshimura, T., Nagamatsu, A., The Vibration Analysis of a Compact Motor by the Substructure Synthesis Method(2nd Report, A Complex Mode Synthesis Method for General Viscous Damping Systems), Trans Jpn. Soc. Mech. Eng., (in Japanese), Vol. 54, No. 504, C(1988), p. 1700 
18. Nagaya, K., Ikeda, S., Vibration and Vibration Isolation of a Motor Due to Whirling of the Shaft with Consideration of Electromagnetic Forces, Trans Jpn. Soc. Mech. Eng., (in Japanese), Vol. 51, No. 472, C(1985), p. 3354

19. Iwata, Y., Sato, H., Komatsuzaki, T., Saito, T., Vibration of Induction Motor Rotor in Rotary Magnetic Field(Case of Two Poles Motor), Trans Jpn. Soc. Mech. Eng., (in Japanese), Vol. 65, No. 638, C(1999), p. 3919

20. Kanzaki, H., Shibayama, J., Watanabe, S., Ichimonji, M., Namaiki, M.,Unsatable Electrical Vibration of an Induction Motor, Trans Jpn. Soc. Mech. Eng., (in Japanese), Vol. 60, No. 578, C(1994), p. 3238

21. Iwatsubo, T., Shiohata, K., Kawamura, S., Hayashi, Y., Vibration Analysis of an Induction Motor under Electromagnetic Force, Trans Jpn. Soc. Mech. Eng., (in Japanese), Vol. 69, No. 680, C(2003), p. 939

22. Adachi, E., Taninaga, S., Experimental Analysis and Reduction of High-Frequency Noise of an Automotive Direct-Current Motor, Trans Jpn. Soc. Mech. Eng., (in Japanese), Vol. 59, No. 567, C(1993), p. 3469

23. Matsubara, K., Ida, M., Obata, T., Avoiding First Mode Resonance in Rigid-Body-Vibration Mode of Rotor for Small Induction Motors, Trans Jpn. Soc. Mech. Eng., (in Japanese), Vol. 64, No. 625, C(1998), p. 3327

24. Yoshikuwa, Y., Imagi, A., Oikawa, T., Effect of Manufacturing Errors on the Electromagnetic Vibration of Brushless DC Motors, Trans Jpn. Soc. Mech. Eng., (in Japanese), Vol. 73, No. 729, C(2007), p. 1346

25. Shiohata, K., Kusama, R. and Ohtsu, S., Experimental Study on Electromagnetic Force Induced Vibration and Noise from Universal Motor with Off-Centered Rotor, Trans Jpn. Soc. Mech. Eng., (in Japanese), Vol. 78, No. 790, C(2012), p. 2028

26. Noda, S., Suzuki, K., Ishibashi, F., Temperature Effect on Electromagnetic Noise of Induction Motors, Trans Jpn. Soc. Mech. Eng., (in Japanese), Vol. 73, No. 730, C(2007), p. 1641

27. Kobayashi, T., Ito, M., Shibukawa, S., Effect of Slot Combination on Acoustic Noise from Induction Motors, IEEE Transaction on Magnetics, Vol. 33, No. 2, 1997, p. 2101

28. Itagaki, T., Igarashi, A., Seki, T., Study on Abnormal Vibration of Motors with Ball Bearings, Trans Jpn. Soc. Mech. Eng., (in Japanese), Vol. 65, No. 631, C(1999), p. 1171

29. Nakamura, K, Generation Mechnism of the Unusual Noise in Axial Flow Fans Driven by Induction Motors, Trans Jpn. Soc. Mech. Eng., (in Japanese), Vol. 62, No. 604, C(1996), p. 4537 